\title{
Erratum to: Molecular analysis of Cercospora beticola isolates for strobilurin resistance from the central High Plains, USA
}

\author{
J. O. Obuya • W. L. Stump • G. D. Franc
}

Published online: 30 July 2016

(C) Koninklijke Nederlandse Planteziektenkundige Vereniging 2016

\section{Erratum to: Eur J Plant Pathol (2016) DOI 10.1007/s10658-016-0959-x}

W.L. Stump (Plant Sciences Department-3354, College of Agriculture and Natural Sciences, University of Wyoming) is added as a second author.

\begin{abstract}
On line 14, the word "developed" is replaced with "used". The new sentence reads: "We used a PCR-RFLP assay that involved an in vitro digestion using Fnu $4 \mathrm{HI}$ restriction enzyme for the rapid molecular detection of G143A mutation in the $C$. beticola population."

\section{Introduction}

Paragraph 5

On line 2, "develop" is replaced with "use".

The new sentence reads: "The objective was to analyze the $C$. beticola population for mutations associated with
\end{abstract}

The online version of the original article can be found at http://dx. doi.org/10.1007/s10658-016-0959-x

\section{J. O. Obuya $(\bowtie)$}

Center for Viticulture and Small Fruit Research, College of Agriculture and Food Sciences, Florida A\&M University, 6505 Mahan Drive, Tallahassee, FL 32317, USA

e-mail: jamesobuya@yahoo.com

W. L. Stump • G. D. Franc

Plant Sciences Department-3354, College of Agriculture and Natural Sciences, University of Wyoming, 1000 E. University Ave, Laramie, WY 82071, USA reduced sensitivity to QoI fungicides, and use a molecular diagnostic assay for the rapid detection of strobilurin resistance."

\section{Results}

Sub-section: "Rapid molecular detection of QoI resistance from $C$. beticola isolates".

On line 2, the word "led" is replaced with "leading".

The new sentence reads: "PCR products obtained from C. beticola QoI-resistant isolates with a SNP at codon 143 were digested using Fnu4HI restriction enzyme leading to at least three fragments that included 144, 112, and 56 base pairs (bp), whereas QoI-sensitive isolates were digested into at least two fragments that included 264 and 56 bp (Fig. 2)."

\section{Discussion}

(i) Paragraph 4

On line 15, the word "developed" is deleted from the sentence.

The new sentence reads: "The PCR-RFLP assay will contribute to the rapid detection of $C$. beticola QoI resistance, because use of cultural techniques such as "poisonmedia" test can be labor intensive, and require a high expertise as well as several months to obtain results."

(ii) Paragraph 5

On line 5, the word "develop" is replaced with "used". The new sentence reads: "Here we used a diagnostic assay that included in vitro digestion with a Fnu4HI restriction enzyme for the rapid molecular detection of G143A mutation associated with $C$. beticola QoI resistance." 